\title{
Cimetidine decreases indomethacin induced duodenal mucosal damage in patients with acute musculoskeletal disorders
}

\author{
R STALNIKOWICZ, D POLLAK, A ELIAKIM, D WENGROWER, A FICH, \\ E GOLDIN, M LIGUMSKY, AND D RACHMILEWITZ
}

From the Departments of Gastroenterology and Orthopedic Surgery, Hadassah University Hospital, Hebrew University-Hadassah Medical School, Jerusalem, Israel

SUMMARY The effect of two doses of cimetidine, $400 \mathrm{mg}$ at night and $400 \mathrm{mg}$ bd, on the protection of indomethacin ( $50 \mathrm{mg}$ tid) induced mucosal damage was evaluated in a double blind study in patients with acute musculoskeletal disorders. Endoscopic mucosal lesions were scored before and after five to seven days of treatment. One hundred and ninety one patients were endoscoped before the trial, 34 $(\mathbf{1 7 \cdot 8} \%)$ had >one erosion and were not recruited. Forty patients were excluded for noncompliance, or lost to follow up. At the second endoscopy, oesophageal, and fundic damage was negligible. Gastric and duodenal lesion score in patients treated with cimetidine $400 \mathrm{mg}$ bd: $2 \cdot 7(0 \cdot 5)$ $(\mathrm{SE}) ; n=42)$ was significantly lower $(\mathrm{p}<0 \cdot 0122)$ than in placebo treated patients: $6 \cdot 1(0 \cdot 9)(n=50)$ or in patients treated with cimetidine $400 \mathrm{mg}$ at night $7 \cdot 1(0 \cdot 8)(\mathrm{n}=21)$. Cimetidine $400 \mathrm{mg}$ bd provided significant protection for the duodenum, but its protection of antral mucosa did not reach statistical significance. There was no correlation between upper gastrointestinal symptoms and endoscopic findings.

Non-steroidal anti-inflammatory drugs (NSAIDs) have become an integral part of the therapy of rheumatologic disorders. Non-steroidal antiinflammatory drugs are now the most widely prescribed of all drugs when grouped by generic categories, not including aspirin, the most commonly used of all drugs, and the prototype of NSAIDs. ${ }^{1}$

Non-steroidal anti-inflammatory drugs damage the gastroduodenal mucosa as has shown endoscopically and by faecal blood loss studies..$^{2-3}$ Significant degree of gastric mucosal damage occurs even after brief periods of time..$^{24}$ In acute patients treated with NSAIDs, the peak gastroduodenal injury is seen during the third and seventh day. ${ }^{2}$ About $30 \%$ of patients taking NSAIDs develop chronic mucosal lesions, but a larger percentage suffers from adverse gastrointestinal symptoms associated with NSAIDs treatment. ${ }^{5-6}$

Address for correspondence: D Rachmilewitz, Dept of Gastroenterology, Hadassah University Hospital, PO Box 12000 , Jerusalem, Israel.

Received for publication 1 June 1988.
Gastric acidity may be an important cause because disruption of the gastric mucosal barrier induced by NSAIDs allows the back diffusion of hydrogen ions resulting in further damage with subsequent tissue injury and bleeding. ${ }^{7-8}$ Suppression of mucosal prostanoid synthesis has also been implicated in the mechanism of NSAIDs induced gastric damage..$^{10}$ In several studies, cimetidine has been reported to have a protective effect on NSAID induced mucosal damage and gastrointestinal symptoms. ${ }^{11-14}$

The purpose of the present study was to evaluate whether the simultaneous administration of cimetidine in two different doses: $400 \mathrm{mg}$ hs or $400 \mathrm{mg}$ bid could prevent gastroduodenal mucosal damage and gastrointestinal symptoms induced by high doses of indomethacin in patients with acute musculoskeletal conditions.

\section{Methods}

SUBJECTS

Patients eligible to participate were men and women, 
over 18 years with a diagnosis of an acute musculoskeletal condition requiring treatment with NSAID. Patients were excluded for the following reasons: pregnancy or lactation, presence of current gastrointestinal symptoms, previous history of gastrointestinal bleeding, regular use in the previous month of NSAIDs or steroids, treatment in the previous month with therapeutic doses of a drug known to promote ulcer healing and concomitant therapy with anticoagulants, phenytoin or theophyllin.

The study was approved by the Human studies Committee of the Hadassah University Hospital and the patients gave a written informed consent.

\section{STUDY DESIGN}

A complete history and physical examination, complete blood count and SMAC II were done before initiation of the study. The SMAC II included the following tests: serum glucose, sodium, potassium, chloride, urea, creatinine, uric acid, total protein, albumin, total bilirubin, cholesterol, alkaline phosphatase, alanine and aspartate amino transferases, LDH, gamma glutamyl transpeptidase, calcium, and phosphorous.

Endoscopic examination was done before starting treatment. A normal gastroduodenal mucosa was required in order to be enrolled in the study. All the qualified subjects received indomethacin $150 \mathrm{mg}$ daily in three divided doses with meals and were randomised into one of three groups in a double blind manner to receive either cimetidine $400 \mathrm{mg} \mathrm{hs}$, cimetidine $400 \mathrm{mg}$ bid, or placebo. Tablets containing $400 \mathrm{mg}$ cimetidine or matching placebo were packed in vials of 16 tablets each. Patients were given two vials and were instructed to take one tablet from one vial before breakfast and from the other vial at ${ }^{*}$ bedtime. Each patient was also asked to record on a diary card the daily frequency and severity: none $=0$; mild $=1$; moderate $=2$; severe $=3$, of the following symptoms: abdominal pain, discomfort, heartburn, nausea, and vomiting. In all patients medication was started not later than 10 hours after the endoscopy.

The duration of treatment was 14 days. Patients had a second endoscopy on the fifth to seventh day of therapy: the appearance of the fundus, antrum, and duodenum were sequentially and separately noted. The presence of erythema, haemorrhages, erosions, or ulcers were recorded and scored: erythema: none $=0$, mild $=1$, moderate/severe $=2$; haemorrhages: none $=0,1=1,2-5=2,6-20=3$, $>20=4$; erosions: none $=0,1=2,2-5=4,6-20=6$, $>20=8$; ulcers: none $=0,1$ ulcer $=10$. Visible vessel $=12$. The mucosa was regarded normal if the total score was less than 1 . For the correlation of symptoms with endoscopic findings the damage was regarded as significant if the score was 3 or higher. During this visit, trial medication and indomethacin tablets were counted and diary cards were changed. Patients were instructed to continue medication for altogether 14 days. At termination of the study, only remaining tablets were counted and diary cards were taken.

All endoscopic examinations were done with an Olympus $\mathrm{GIFQ}_{10}$ fibreoptic endoscope. Premedication consisted of cetacaine spray (Cetylite Indust INC N-S, USA) to the oropharynx and intravenous diazepam 5-10 mg.

\section{STATISTICAL METHODS}

Pretrial and demographic characteristics were examined for comparability of the treatment groups. The sum of the endoscopy ratings of erythema, haemorrhages, erosions and ulcers was combined by site and overall to obtain an endoscopic summary score for week 1 . The weighted average of the severity ratings for pain, heartburn, discomfort, nausea, and vomiting was used as a symptom summary score at weeks 1 and 2 . The Mann-Whitney $\mathrm{U}$ test was used to examine the treatment differences in the endoscopic summary scores and symptom summary scores. Presence and absence of the symptoms and the amount of endoscopic damage were examined for differences between treatments by the $\chi^{2}$ test. The statistical significance level was set at $\mathrm{p}=0.025$.

\section{STUDY POPULATION}

One hundred and ninety one patients with acute musculoskeletal disorders were referred by orthopaedic surgeons to the study. They were all endoscoped. Thirty four patients were found to have abnormal mucosa in the stomach or duodenum. These patients were not eligible for the study.

Of the 157 patients enrolled in the study, 40 patients were excluded because of lost follow up or non-compliance with either indomethacin or with the coded medication. The musculoskeletal disorders of the patients who concluded the trial are detailed in Table 1.

An interim analysis was performed when 73 patients were eligible for analysis after the second endoscopy: 30 in the placebo, 21 in the cimetidine 400 $\mathrm{mg}$ hs and 22 patients in the cimetidine $400 \mathrm{mg}$ bid treatment group. This analysis revealed that there was no difference in total lesion score in patients treated with cimetidine $400 \mathrm{mg}$ hs or placebo: $7 \cdot 1$ $(0 \cdot 8)(\mathrm{SE})$ and $9 \cdot 1(4 \cdot 8)$ respectively and therefore the cimetidine $400 \mathrm{mg}$ hs dose was omitted when further recruitment took place. The double blindness between the remaining two treatment groups, however, was maintained. 
Table 1 Age, sex, and musculoskeletal condition of subjects concluding one week treatment

\begin{tabular}{|c|c|c|c|c|c|c|}
\hline \multirow[b]{3}{*}{ Treatment } & \multirow{2}{*}{\multicolumn{2}{|c|}{$\frac{\text { Cimetidine }}{400 m g h s}$}} & \multirow{2}{*}{\multicolumn{2}{|c|}{$400 \mathrm{mg}$ bid }} & \multirow{2}{*}{\multicolumn{2}{|c|}{ Placebo }} \\
\hline & & & & & & \\
\hline & $n$ & $\%$ & $n$ & $\%$ & $n$ & $\%$ \\
\hline Total & 21 & $100 \cdot 0$ & 42 & $100 \cdot 0$ & 50 & $100 \cdot 0$ \\
\hline \multicolumn{7}{|l|}{ Sex } \\
\hline Male & 9 & & 22 & & 28 & \\
\hline Female & 12 & & 20 & & 22 & \\
\hline \multicolumn{7}{|l|}{ Age (y) } \\
\hline Mean & $42 \cdot 2$ & & $39 \cdot 0$ & & $39 \cdot 3$ & \\
\hline SD & $12 \cdot 4$ & & $15 \cdot 2$ & & $17 \cdot 0$ & \\
\hline Range & $20-60$ & & $18-67$ & & $18-78$ & \\
\hline \multicolumn{7}{|l|}{ Musculoskeletal condition } \\
\hline Neuropathy & 3 & $14 \cdot 2$ & 6 & $14 \cdot 2$ & 5 & $10 \cdot 0$ \\
\hline $\begin{array}{l}\text { Periarthritis/soft tissue } \\
\text { inflammation }\end{array}$ & 3 & $14 \cdot 2$ & 5 & 11.9 & 5 & $10 \cdot 0$ \\
\hline Joint pain syndrome & 6 & $28 \cdot 6$ & 12 & $28 \cdot 5$ & 14 & $48 \cdot 3$ \\
\hline Back pain & 8 & $38 \cdot 0$ & 18 & $42 \cdot 8$ & 22 & $44 \cdot 0$ \\
\hline Other & 1 & $4 \cdot 8$ & 1 & $2 \cdot 3$ & 4 & 8.0 \\
\hline
\end{tabular}

\section{Results}

There was no difference in the sex or age distribution among patients in the three treatment groups (Table 1).

The mean total damage score of all gastric and duodenal lesions in the placebo treated patients $-6 \cdot 1$

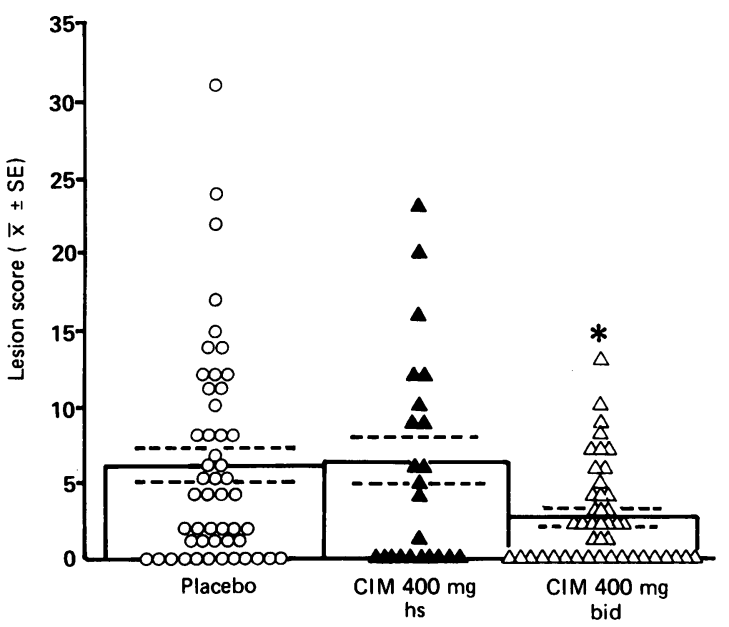

Fig. 1 Total endoscopic score of gastroduodenal lesions. Patients with acute musculoskeletal condition were treated with indomethacin $50 \mathrm{mg}$ tid together with cimetidine $400 \mathrm{mg}$ hs, $400 \mathrm{mg}$ bid, or placebo. Endoscopy was done after five to seven days. The presence of erythema, haemorrhages, erosions, and ulcers in stomach and duodenum was scored as described in Methods. Results are mean (SE). Points represent scores of individual subjects. *Significantly different from placebo $p<0.0122$ (Mann-Whitney $U$ test).

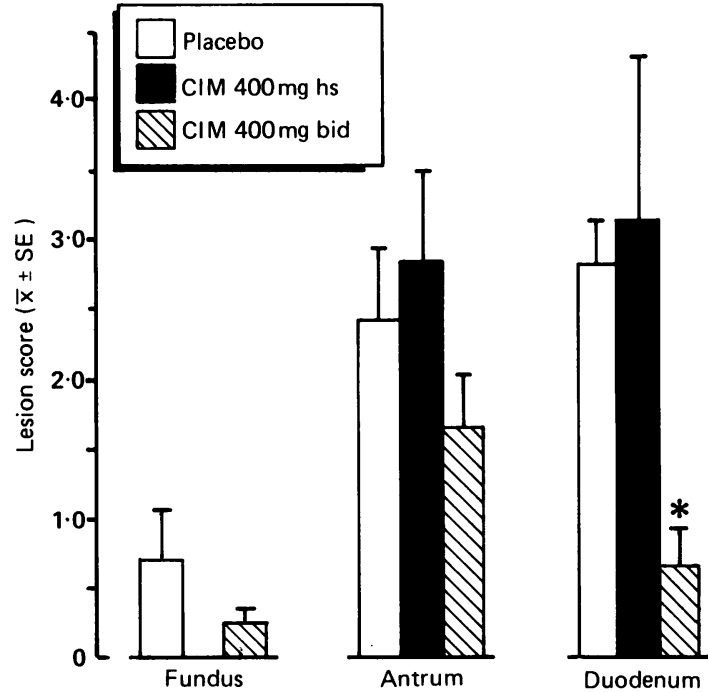

Fig. 2 Endoscopic score of lesions in the stomach antrum, fundus, and in the duodenum. Patients with acute musculoskeletal condition were treated with indomethacin 50 $\mathrm{mg}$ tid together with cimetidine $400 \mathrm{mg} \mathrm{hs,} 400 \mathrm{mg}$ bid, or placebo. Endoscopy was done after five to seven days. The presence of erythema, haemorrhages, erosions, and ulcers in stomach and duodenum was scored as described in Methods. Results are mean endoscopic score (SE) for each region. *Significantly different from placebo $p=0.0004$ (MannWhitney $U$ test).

(0.9) (SE) and in the cimetidine $400 \mathrm{mg}$ hs treated patients $7 \cdot 1(0 \cdot 8)$ was significantly higher $-\mathrm{p}=0 \cdot 0122$ (Mann-Whitney U test) - than that in the cimetidine $400 \mathrm{mg}$ bid treated patients $-2.7(0 \cdot 5)$ (Fig. 1). Analysis of the regional total lesion scores as illustrated in Figure 2 indicate that damage to antral mucosa was slightly reduced by cimetidine but this was not significant. Significant protection was afforded, however, by cimetidine $400 \mathrm{mg}$ bid to duodenal mucosa $(p=0 \cdot 0004)$. Only one patient was found to have gastric ulcer, and he was treated with placebo. Three subjects in the placebo group and two in the cimetidine $400 \mathrm{mg}$ hs, but none in the cimetidine $400 \mathrm{mg}$ bid, developed duodenal ulcer.

Cimetidine did not ameliorate gastrointestinal symptoms induced by indomethacin during the first week of the study. The incidence of the symptoms scored - pain, heartburn, abdominal discomfort, nausea, and vomiting - was similar in the three treatment groups (Table 2). In those patients who also concluded the second week of treatment with cimetidine $400 \mathrm{mg}$ bid, a trend towards reduction in global symptom score was noted: $0.78(0.88)(\mathrm{SD})$ $n=28)$ as opposed to $0.96(0.83)$ in the same subjects after the first week. There was also no correlation between upper gastrointestinal symptoms and endo- 
Table 2 Presence of gastrointestinal symptoms in patients concluding one week treatment

\begin{tabular}{|c|c|c|c|c|c|c|}
\hline & \multicolumn{2}{|c|}{$400 \mathrm{mg}$ nocte } & \multicolumn{2}{|c|}{$400 \mathrm{mg}$ bid } & \multicolumn{2}{|c|}{ Placebo } \\
\hline & $n$ & $\%$ & $n$ & $\%$ & $n$ & $\%$ \\
\hline Pain & 10 & $43 \cdot 5$ & 17 & $38 \cdot 6$ & 17 & $34 \cdot 7$ \\
\hline Heartburn & 5 & $21 \cdot 7$ & 12 & $27 \cdot 3$ & 16 & $32 \cdot 7$ \\
\hline Discomfort & 7 & $30 \cdot 4$ & 20 & $45 \cdot 5$ & 21 & 42.9 \\
\hline Nausea & 8 & $34 \cdot 8$ & 15 & $34 \cdot 1$ & 23 & $46 \cdot 9$ \\
\hline Vomiting & 4 & $17 \cdot 4$ & 6 & $13 \cdot 6$ & 4 & $8 \cdot 2$ \\
\hline
\end{tabular}

scopic findings, irrespective of the treatment the patients were receiving.

\section{Discussion}

Numerous new NSAIDs have been developed with the two-fold objective of producing greater antiinflammatory effect than aspirin with less gastrointestinal toxicity. A significant degree of gastric mucosal haemorrhage and ulceration was shown, however, in patients and in normal volunteers taking these agents even for brief periods of time. ${ }^{23}$ is Differences in the degree of injury do exist among different drugs ${ }^{2}$ and for each drug, the severity of mucosal damage is dose dependent. ${ }^{2}$

Indomethacin in doses of 100 to $150 \mathrm{mg}$ a day has been reported to cause a similar degree of mucosal injury to that induced by aspirin $3600 \mathrm{mg}$ a day. ${ }^{16} \mathrm{In}$ the present study, the high dose of indomethacin was used with the assumption that protection provided against this dose will definitely be effective against a lower dose. Indomethacin has been shown to induce more gastrointestinal side effects such as nausea, epigastric pain, heartburn, and abdominal discomfort than the newer NSAIDs. ${ }^{6}$

Several studies evaluated whether coadministration of NSAIDs and other drugs, such as $\mathrm{H}_{2}$ antagonists, antacids, prostaglandins and their synthetic analogues would minimise NSAIDs induced gastrointestinal damage. ${ }^{11-14}{ }^{17-21}$ Cimetidine, has been reported to have a protective effect on NSAID induced mucosal damage, determined endoscopically or through analysis of faecal blood loss. ${ }^{11-14}$ Most of these studies were carried out in experimental animals, however, or only in a small number of subjects and in patients taking aspirin chronically. ${ }^{11-14}$

Indomethacin $150 \mathrm{mg}$ a day when administered for five to seven days induced significant gastroduodenal injury in about $50 \%$ of the subjects. Non-steroidal anti-inflammatory drugs are usually believed to induce mainly gastric damage. The results obtained in the present study in the placebo treated patients clearly show that in indomethacin treated patients duodenal mucosal injury is as common and as severe as gastric mucosal injury. In a similar way we have recently shown in a retrospective study that duodenal injury induced by other NSAIDs is also as common as the gastric damage..$^{22}$

Upper gastrointestinal symptoms are regarded by many as an indication of the presence of gastroduodenal mucosal injury. The results reported herewith, clearly indicate that there is no correlation between upper gastrointestinal symptoms and the presence or severity of objective endoscopically proven mucosal damage. Moreover, cimetidine, when coadministered in a dose which afforded effective mucosal protection, did not affect the subjective symptoms.

Seventeen per cent of the subjects without any gastrointestinal complaint and therefore with presumably normal mucosa were found on the first endoscopy before inclusion in the study to have gastroduodenal mucosal damage. Most of these subjects had erosions in the stomach and/or duodenum but three had duodenal ulcer, one gastric ulcer, and one ulcerated leiomyoma. This finding concurs with recent observation of Akdamar et al ${ }^{23}$ and Woltjen et $a l^{24}$, who found an even higher incidence of mucosal lesions in normal asymptomatic volunteers.

In addition to suppression of mucosal prostanoids ${ }^{19}$ indomethacin stimulate basal gastric acid secretion, ${ }^{25}$ and like aspirin may impair acid induced bicarbonate secretion, ${ }^{26}$ which can definitely contribute to the pathogenesis of the mucosal injury induced by this drug. The mechanism whereby protection is afforded by cimetidine can be mediated through its antisecretory effect. ${ }^{7}$ By raising the intragastric $\mathrm{pH}$, cimetidine given twice daily could decrease the lipid solubility of indomethacin. As indomethacin's pKa is 4.5 at $\mathrm{pH}$ much above 4.5 more than half of the indomethacin would become ionised and therefore be not available for direct absorption into the gastroduodenal mucosa by lipid solubility. Cimetidine protective effect on the gastric mucosal barrier ${ }^{8}$ and its stimulation of gastric prostanoid synthesis, ${ }^{27}$ may also explain its protection against the indomethacin induced damage. The lack of protection provided by cimetidine $400 \mathrm{mg}$ hs suggests that cimetidine's antisecretory effect is the main property responsible for its protection against NSAIDs induced damage.

This work was supported by grants from Smith Kline \& French, Philadelphia, USA; and by a grant given by Ruth and Arthur Balsam in memory of Dr Viktor Miller. This paper was presented at the annual meeting of the American Gastroenterological Association, San Francisco, 1986, and was published as an abstract in Gastroenterology 1986; 90: 1956. 


\section{References}

1 Drug utilization in the United States by categories, 1981. 3rd Annual Review. Washington, DC: National Center of Drugs and Biologies, 1982, Table V, 17.

2 Lanza FL. Endoscopic studies of gastric and duodenal injury after the use of ibuprofen, aspirin, and other non steroidal antiinflammatory agents. Am J Med 1984; IA: 19-24.

3 Loebl DH, Craig RM, Culic DD. Gastrointestinal blood loss: effect of aspirin, fenoprofen and acetaminophen in rheumatoid arthritis as determined by sequential gastroscopy and radioactive fecal markers. JAMA 1977; 237: 976-81.

4 O'Laughlin JC, Hoftiezer JW, Ivey KJ. Effect of aspirin on the human stomach in normals: endoscopic comparison of damage produced one hour, 24 hours and 2 weeks after administration. Scand J Gastroenterol [suppl] 1981; 67: 211-4.

5 Caruso I, Bianchi PG. Gastroscopic evaluation of antiinflammatory agents. $\mathrm{Br} \mathrm{Med} J 1980 ; 280: 75-8$.

6 Pemberton RE, Strand JM. A review of upper gastrointestinal effects of the newer non steroidal antiinflammatory agents. Dig Dis Sci 1979; 24: 53-63.

7 Cooke AR. The role of acid in the pathogenesis of aspirin induced gastrointestinal erosions and hemorrhage. Am J Dig Dis 1973; 18: 225-37.

8 Cooke AR. Gastric damage by drugs and the role of the mucosal barrier. Aust NZJ Med 1976; 6: 26-32.

9 Vane JR. Inhibition of prostaglandin synthesis as a mechanism of action for aspirin like drugs. Nature 1971; 231: 232-5.

10 Rachmilewitz D, Ligumsky M, Fich A, Goldin E, Eliakim A, Karmeli F. Role of endogenous gastric prostanoids in the pathogenesis and therapy of duodenal ulcer. Gastroenterology 1986; 90: 963-9.

11 Welch RW, Bentch LH, Harris SC. Reduction of aspirin induced gastrointestinal bleeding with cimetidine. Gastroenterology 1978; 74: 459-63.

12 Mann NS, Sachdev AJ. Acute erosive gastritis induced by aspirin ketoprofen, ibuprofen and naproxen: its prevention by metiamide and cimetidine. South Med J 1977; 70: 562-4.

13 MacKercher PA, Ivey KJ, Baskin WM, Krause WJ. Protective effect of cimetidine on aspirin induced gastric mucosal damage. Ann Intern Med 1977; 87: 676-9.

14 Lanza FL, Roger GL, Nelson RS. Effect of a cimetidineantacid regimen on the gastric and duodenal mucosal injury seen with aspirin and other non steroidal antiinflammatory agents [Abstract]. Gastroenterology 1983; 84: 1224.
15 Silvoso GR, Ivey KJ, Butt JH, et al. Incidence of gastric lesions in patients with rheumatic disease on chronic aspirin therapy. Ann Intern Med 1979; 91: 517-20.

16 Lanza FL, Roger GL, Nelson RS, Chen TT, Seckman CE, Rack MF. The effects of ibuprofen, indomethacin, aspirin, naproxen, and placebo on the gastric mucosa of normal volunteers. A gastroscopic and photographic study. Dig Dis Sci 1979; 24: 823-8.

17 Graham DY, Smith JL, Dobbs SM. Gastric adaptation occurs with aspirin administration in man. Dig Dis Sci 1983; 28: 1-6.

18 Konturek SJ, Kwiecien N, Obtulowicz W, Polanski M, Kopp B, Oleksy J. Comparison of prostaglandin $\mathrm{E}_{2}$ and ranitidine in prevention of gastric bleeding by aspirin in man. Gut 1983; 24: 89-93.

19 Cohen MM, McCready DR, Clarck L, Sevelius H. Protection against aspirin induced antral and duodenal damage with enprostil. A double blind endoscopic study. Gastroenterology 1985; 88: 382-6.

20 Lanza FL. A double blind study of prophylactic effect of misoprostol on lesions of gastric and duodenal mucosa induced by oral administration of tolmetin in healthy subjects. Dig Dis Sci 1986; 31: 1315-65.

21 Johansson C, Kollberg B, Nordemar R, Samuelson $K$, Bergstrom S. Protective effect of prostaglandin $E_{2}$ in the gastrointestinal tract during indomethacin treatment of rheumatic diseases. Gastroenterology 1980; 78: 479-89.

22 Eliakim R, Ophir M, Rachmilewitz D. Duodenal mucosal injury - common consequence of therapy with non-steroidal anti-inflammatory drugs. J Clin Gastroenterol 1987; 9: 395-9.

23 Akdamar K, Ertan A, Agrawal NM, McMahon FG, Ryan J. Upper gastrointestinal endoscopy in normal asymptomatic volunteers. Gastrointest Endosc 1986; 32: 78-80.

24 Woltjen JA, Barber GB, Leese PT, Burger AE. Prevalence of abnormal esophageal, gastric and duodenal mucosa in normal healthy males [Abstract]. Gastroenterology 1986; 90: 1695.

25 Levine RA, Schwartzel EH. Effect of indomethacin on basal and histamine stimulated human gastric acid secretion. Gut 1984; 25: 718-22.

26 Flemstrom G, Kivilaakso E. Determination of a $\mathrm{pH}$ gradient at the luminal surface of rat duodenum in vivo and its dependence on mucosal alkaline secretion. Gastroenterology 1983; 84: 787-94.

27 Branski D, Sharon P, Karmeli F, Rachmilewitz D. Effect of cimetidine on human gastric and duodenal prostanoid synthesis. Scand J Gastroenterol 1984; 19: 457-60. 